\title{
Leitura como formação, formação como leitura: processos narrativos/formativos em questão
}

\author{
Eda Maria de Oliveira Henriques \\ Universidade Federal Fluminense \\ Helena Amaral da Fontoura \\ Universidade Estadual do Rio de Janeiro
}

\section{Resumo}

Este artigo apresenta pesquisas realizadas com professoras da rede pública do Distrito Federal e com professores egressos de licenciatura em pedagogia do Rio de Janeiro, com a proposta de resgatar leituras e narrativas sobre suas experiências de formação. Nessa perspectiva, buscamos pensar as concepções dos sujeitos sobre suas experiências de leitura ao longo de sua trajetória escolar, bem como compreender a existência de um diálogo dessas leituras com suas práticas pedagógicas atuais. Concluímos que a narrativa se revelou um importante espaço para o estabelecimento de novas possibilidades de leitura das relações entre memórias escolares relacionadas à leitura e questões da prática profissional.

Palavras-chave: Narrativas. Formação docente. Leitura. 


\section{Reading as training, training as reading: narrative/formative processes in question}

This article presents research conducted with teachers form the public school system in the Brazilian Federal District and teachers who majored in education in Rio de Janeiro. The idea was to reveal interpretations and narratives of their experiences while in training. In this perspective, we attempted to think about the objects' perceptions around their reading experiences throughout their school history, as well as comprehend the existence of a dialog between these experiences and their current educational practices. We concluded that narrative showed itself as an important space for the establishment of new possibilities of interpreting the relations between school memories related to reading and matters related to professional practice.

Keywords: Narratives. Teacher training. Reading.

\section{Lectura como formación, formación como lectura: narrativa-formante, procesos en cuestión}

Este artículo presenta investigaciones llevadas a cabo con profesores de la red pública del Distrito Federal y con graduados de licenciatura en pedagogía en RJ, con la propuesta de rescate de lecturas y narraciones sobre sus experiencias de formación. Intentamos pensar las concepciones acerca de sus experiencias de lectura a lo largo de su carrera en la escuela, así como entender la existencia de un diálogo de las mismas con sus actuales prácticas pedagógicas. Concluimos que la narrativa se ha evidenciado como un importante espacio para el establecimiento de nuevas posibilidades de lectura de las relaciones entre recuerdos de la escuela relacionadas con la lectura y las cuestiones de la práctica profesional.

Palabras-clave: Narrativas. Formación del profesorado. Lectura. 


\section{Introdução}

Escrever é sempre colocar em palavras o que pensamos e sentimos e, quando colocamos no papel, já não nos pertence, passa a ser de quem nos lê e de quem nos interpreta. Por isso, é necessário precisar sobre o que falamos, pelo menos para garantir um início de diálogo. Assim, tratamos neste trabalho de uma inserção de quem faz e pensa a formação de professores de forma qualificada e contextualizada. O significado do desenvolvimento pessoal e profissional, mesclado à dimensão coletiva do ensinar e do aprender, não comporta a visão de processo cumulativo de conhecimentos dispostos de forma compartimentada: cursos, teorias, livros e técnicas. A concepção e análise dos contextos e relações sociais que produzem um conjunto de valores, saberes e atitudes imprimem à educação sua dimensão de experiência humana.

Afirmamos, no presente trabalho, que é importante compreender a leitura na sua estreita relação com o processo de formação, nosso foco de interesse nesse relato, como uma experiência na qual estão envolvidos processos dinâmicos de interpretação e atribuição de sentidos, em que ler, como diz Larrosa (2002), é realizar a experiência de se pensar pensando o mundo, num ininterrupto processo de constituição de si. Entretanto, o que significa pensar a leitura como formação? De acordo com o autor, significa pensar a leitura como algo que nos constitui, nos forma, e, em alguns casos, nos (de)forma ou nos (trans)forma, mas que sempre põe em questão aquilo que somos.

A partir das contribuições de autores que conjugam o potencial da relação entre leitura e formação para a questão da formação de professores, este artigo traz o relato e as reflexões de pesquisas que procuram resgatar as leituras e as narrativas de professores sobre sua própria experiência de formação. Nessa perspectiva, buscou-se identificar e analisar concepções de professores de ensino básico sobre suas experiências de leitura ao longo de sua trajetória escolar, bem como compreender a existência ou não de um diálogo das leituras com suas práticas pedagógicas atuais. Dessa forma, a leitura do professor sobre suas práticas pedagógicas passa necessariamente por uma narrativa que resgata trajetórias de formação.

As pesquisas aqui trazidas têm, então, como foco principal relacionar experiências em leitura e processos formativos docentes, estabelecendo implicações entre esses espaços de aprendizagem do fazer docente, que considera - que vivemos e fazemos parte integrante da forma como compreendemos a docência ou a leitura que dela fazemos e como a praticamos. Apostamos na narrativa como proposta metodológica, defendendo a importância de se utilizarem processos narrativos com professores/as em formação e em atuação, por seu 
valor de empoderamento dos sujeitos quando entram em contato - escrevendo ou falando - com suas crenças, práticas e valores, fortalecendo essas práticas e a possibilidade de sua permanência no magistério de forma qualificada. Como nosso foco é leitura e formação, como processos de aquisição enquanto formas de perceber e agir no mundo, tais questões demandam um olhar mais aprofundado sobre uma ideia de leitura que possa transcender a leitura do texto escrito, mas que, ao mesmo tempo, numa relação complementar e dialética, a enriqueça e resgate sua complexidade.

\section{Diálogos teórico-metodológicos: um aprofundamento}

Quando Vygotsky (2005) traz a ideia de que as relações do homem com o mundo são mediadas pela linguagem e que o desenvolvimento do pensamento é determinado pela experiência sociocultural da criança e pelos instrumentos linguísticos do pensamento, abre caminho para a discussão sobre a leitura no seu potencial de rica e complexa relação com o pensar. Uma leitura sem pensamento se reduz a mera decodificação mecânica da escrita e a um grande desperdício desse poderoso instrumento da relação com o pensar, com reflexos no potencial de compreensão e interpretação do espectro de disciplinas do contexto escolar e suas consequências para o desenvolvimento do aluno. Tal questão remete ao amplo estudo realizado pelo autor sobre a relação pensamento e linguagem, um dos temas abordados ao longo do texto.

Refletindo sobre a importância do resgate da afirmação de Paulo Freire de que a leitura de mundo antecede a leitura da palavra, Yunes (2005) aponta para o fato de que, como o relato de mundo sempre se apresenta sobre vários suportes, inclusive o escrito, perdemos a capacidade de viver nossa história como um texto, que inscrevemos no social. Assim também nos afastamos das nossas memórias e do que elas representam para uma sempre renovada leitura do nosso presente e dos nossos processos de formação.

A esse respeito, Larrosa (1996) retoma a possibilidade de não só se pensar a leitura como formação, mas também a formação como leitura, destacando a possibilidade e a necessidade de um debruçar e de uma escuta atenta ao que nossos processos de formação têm a nos dizer, construindo uma relação permanente de novas produções de sentido sobre eles. Ler não é apenas decodificar palavras, não se reduzindo a conhecimentos fonéticos ou semânticos. Mesmo assim, muitas práticas pedagógicas de alfabetização ainda se baseiam na decodificação do alfabeto e em outros códigos considerados necessários ao cotidiano. Nesse processo de formação, de acordo com Yunes (2005), alunos 
acabam se transformando em ledores, ao invés de leitores, de forma que frases simples, como 'saída à esquerda', podem tornar-se difíceis de entender. Se o processo de leitura não consiste apenas no agrupamento de letras em palavras e de palavras em frases, o que seria ler? Para nós, ler é compreender o texto como um todo: é entender o que foi escrito, o que foi preexistente a ele e o que não está completamente à mostra nele.

Larrosa (1996) diz que a leitura é uma atividade de interação, em que leitor e texto, que nem sempre é escrito, interagem entre si. Portanto, cada sujeito terá uma leitura distinta de um mesmo texto. Ler é construir um sentido, e, para isso, de acordo com Yunes (2002), a leitura articula memórias, saberes, cultura e aprendizagens, levando a pensar que o leitor é quem traz a significação ao texto, enfocando-o, relacionado a diversos universos preexistentes, que expressam a transdisciplinaridade do conhecimento humano.

De acordo com Vygotsky (1999), a leitura é uma atividade cultural complexa e como tal deveria ser ensinada. Questão presente desde muito cedo nas preocupações do autor, quando ainda em trabalho acadêmico de final de curso, afirma que nenhuma obra literária existe sem o leitor, pois ele a reproduz, recria e elucida. Embora aqui o jovem Vygotsky tenha feito essa afirmação com a preocupação de defender uma concepção analítica que denominou de crítica de leitor, na qual a obra de arte é apenas uma possibilidade que o leitor realiza, o que parece estar em jogo é como essa forma de compreender a relação entre leitor, autor e sua obra aponta para a questão da relação íntima entre texto, contexto e subjetividade. Nesta perspectiva, para o autor, a obra de arte, uma vez criada, não pode existir sem o leitor, uma vez que o autor pode inclusive desconhecer a profundidade do que criou e levar o crítico leitor a revelações das quais ele, como autor, nem sequer suspeitava. Isso faz com que a força da obra não esteja naquilo que o autor subentendeu por ela, mas na maneira como age sobre o leitor.

Desse modo, a leitura não fica presa a um modelo semântico fechado, mas se abre sempre e infinitamente para a diversidade e universos onde o leitor a enfoca. Universos que podem conter experiências de vida, experiências de leitura, experiências em torno do ensinar e do aprender.

Assim, é o texto que se oferece com seu potencial simbólico na construção de outras narrativas, para a superação da 'angústia da palavra' (Vygotsky, 1999), do inexprimível de alguns sentidos, do indizível do discurso interior. Aqui o autor antecipa um tema que será um de seus principais objetos de estudo, a relação pensamento e linguagem, enfatizando que a complexidade da passagem entre pensamento e palavra se deve, entre outras coisas, ao fato de que o pensamento é sempre algo integral, condensado, maior em sua extensão e volume do que uma palavra isolada. 0 que no pensamento existe em simultaneidade, na linguagem 
se desenvolve sucessivamente. Nesse sentido, há uma imperfeição da palavra na possibilidade de expressar o pensamento, pois o pensamento nunca é igual ao significado direto das palavras.

A condensação de sentidos contidos em um único pensamento faz com que na sua transformação em palavras sempre exista algo da ordem do indizível. É o que Vygotsky (2005) vai chamar de subtexto. Ao que o autor acrescenta que, para entendermos o discurso do outro, não é necessário entendermos apenas algumas palavras, mas é preciso entender também seu pensamento e principalmente o motivo que o levou a emiti-lo. Assim, a compreensão efetiva e plena do pensamento de outrem só se torna possível quando descobrimos o que Vygotsky (2005) denomina de 'causa profunda afetivo-volitiva', que encerra o desejo que está na origem de todo o pensamento.

Vygotsky (2001), em seu texto “Educação Estética”, vai colocar a escola como espaço privilegiado do desenvolvimento da educação estética, mas vai também realizar uma crítica contundente e atual à forma como, de modo geral, a escola trabalha junto ao aluno com a literatura infantil. A esse respeito, diz o autor que a repugnância que noventa e nove por cento dos alunos experimentam pela literatura clássica tem sua origem na existência de um direcionamento pedagógico para uma interpretação do texto, que o transforma "em uma espécie de ilustração para uma tese moral de cunho geral" (Vygotsky, 2001, p.328). Assim, a busca de uma mensagem edificante, o direcionamento para a identificação da 'moral da história' são encaminhamentos que, segundo o autor, exercem uma influência devastadora sobre o próprio surgimento da percepção artística e da relação estética com 0 objeto.

Deste modo, um indivíduo aprende a ler quando relaciona o que lê com seu conhecimento de mundo, ou seja, com suas vivências. É a leitura vivida como experiência, transformando a simples decodificação de palavras em uma tarefa de descoberta.

A experiência de leitura é uma atividade de interiorização de conhecimentos. Larrosa (1996) diz que ler é traduzir de forma que produza sentido a quem lê. Entretanto, isso não equivale a olhar o texto apenas analiticamente. Para esse autor, a compreensão está no ato de escutar o que o texto tem a dizer. Yunes também discorre sobre isto: "ler é um ato homólogo ao de pensar, só que com uma exigência de maior complexidade, de forma crítica e desautomatizada." (Yunes, 2005, p.16)

Pensar na leitura como formação é pensar nela como uma experiência: uma experiência que nos submete à transformação, que não é controlada empiricamente. Assim, "para que a leitura seja uma experiência, tem de afirmar a sua multiplicidade, mas uma multiplicidade dispersa e nômade, que sempre se 
descola e escapa ante a qualquer tentativa de reduzi-la." (Larrosa, 1996, p.148)

Para sermos capazes de enxergar o que a experiência de leitura promoveu em um certo indivíduo, devemos olhar suas memórias, escutar as histórias de cada vivência, procurando encontrar as modificações que a leitura foi capaz de fazer. Nossa vida é formada por narrativas, que, ao longo de experiências de formação, podem adquirir novas leituras.

Benjamin (1985) nos ensina que as histórias mantêm-se vivas na memória dos que as ouvem quando são assimiladas às suas experiências pessoais. Esse autor traz uma reflexão sobre a extinção da arte de narrar, e podemos dialogar com ele, trazendo que viver a experiência de narrar para professores em formação constante pode se tornar um espaço privilegiado para a criação e circulação de memórias e histórias, de vida e de formação, resgatando esta arte de narrar como ferramenta formativa.

Diz ainda que um acontecimento vivido é finito ao passo que um acontecimento lembrado não tem limites, é uma chave para tudo o que veio antes e pode vir depois; o que o autor quer dizer é que tornar o passado presente, além de rememorar um fato evocado, navega no tempo e se desloca no espaço, pois conecta lembranças, palavras e imagens, relacionando sentidos e sentimentos. Fala também do 'trabalho de Penélope', da reminiscência, um sempre refazer das teias que sustentam nossa construção pessoal, profissional, afetiva e social.

Seríamos então eterno/as construtores/as de nossas tapeçarias a serem desmanchadas à espera de uma idealização? Que lugar ocupamos como professores e professoras em um mundo em crise? Pensamos a ideia de labirinto inspirada em Benjamin (1985), que representa uma contraposição à compreensão do tempo histórico forjado na modernidade. Enquanto este é linear, vazio, homogêneo; o tempo labiríntico é múltiplo, não linear, repleto de possibilidades inscritas nas relações do presente com passado e futuro. Para decifrá-lo, é necessária a aprendizagem da leitura dos sinais, dos signos, das marcas, dos gestos, dos silêncios.

Uma narrativa pode ser usada como sinônimo de história, na acepção de relato de ações que envolvem seres humanos e situações vividas ou imaginadas. A narrativa é inerente à ação humana e, portanto, deve ser estudada dentro dos seus contextos social e educativo. Connelly e Clandinin (1986) atribuem grande valor ao contexto em que se conta a narrativa, às razões que levam o narrador a contá-la e ao tipo de audiência a que se destina. Em Clandinin e Connelly (1991), os termos narrativa e história qualificam um fenômeno básico da vida e da educação; embora os autores apresentem estes termos como sinônimos, explicitam contextos específicos para a sua utilização. Assim, propõem a utilização: a) do termo história quando os textos se referem a situações concretas, 
vividas por sujeitos particulares em momentos específicos; b) do termo narrativa quando se referem à investigação ou à metodologia de investigação. No campo da educação, as narrativas têm sido utilizadas: a) na construção de conhecimentos e no desenvolvimento de capacidades e atitudes; bl no desenvolvimento pessoal e profissional de professores; e c) na investigação educativa, entre outros.

Segundo Galvão (2005), a narrativa, oral ou escrita, pode constituir um método poderoso de investigação em educação. A autora fala do conceito de narrativa fundamentada em vários autores, buscando compreender as potencialidades da narrativa em estudos com professores. Apresenta três potencialidades da narrativa - como processo de investigação em educação, como processo de reflexão pedagógica e como processo de formação - ilustradas com episódios relatados por professores.

Para Bragança (2009), o processo de formação não acaba na universidade, começa bem antes dela, por meio da construção de saberes baseados nas experiências vividas, na interação com outros educadores, e permanece durante toda a sua vida. Sendo assim, devemos pensar como ela mesma cita a formação: como um conceito amplo ligado à vida do/a professor/a, à instituição escolar e à sociedade como um todo. A autora trata também a narrativa como condição da memória, que possibilita pensar as identidades profissionais em relação à prática e às dificuldades encontradas no dia a dia profissional. Diz ainda a autora que a formação deixa de ser tratada como processo restrito aos espaços acadêmicos e passa a ser vista como um continuum, que tem início muito antes da entrada na escola e se prolonga por toda a vida do professor, sendo assim um conceito amplo ligado à vida dele, à instituição escolar e à sociedade como um todo.

Um professor narrador é aquele que faz da escola um lugar de criação e recriação de experiências, na medida em que não apenas reproduz os conteúdos dos livros didáticos, mas que, mediante a reflexão de sua prática, as recriam e as reinventam, mudando o cotidiano escolar de forma a adaptá-lo para a realidade do aluno e da sociedade em que a escola está inserida. Construir, ler ou ouvir narrativas, em contextos de formação inicial ou continuada de professores, traz potencialidades imensas. Ao contarmos acontecimentos relevantes para nós, fazemos mais do que registrar esses acontecimentos; podemos mudar nossas maneiras de agir ou pensar sobre nossas ações, etapas diferentes de nosso processo de formação. Podemos desenvolver uma atitude mais crítica sobre nosso fazer, ou auxiliar colegas que compartilham conosco espaços narrativos a repensarem suas práticas e crenças sobre as possibilidades de um fazer docente mais emancipatório e construtivo.

Quando escolhemos episódios narrativos, lembramos situações vividas em nossa trajetória de vida, que trazem implicações em nossos modelos de atuação 
docente; explicitamos conhecimentos pedagógicos construídos em nossas experiências, tornando possível entendermos de onde podem vir ações e reações aparentemente inexplicáveis. Tomamos consciência do que fazemos, questionamos o que sabemos e o que não sabemos, buscamos mudanças, estabelecemos compromissos, definimos metas, enfim, podemos nos posicionar de uma forma propositiva frente aos desafios cotidianos presentes em nosso fazer.

Quem lê, ouve ou analisa narrativas pode aprofundar conhecimentos a respeito de práticas em ensino-aprendizagem, na relação professor-aluno, nas interações que acontecem nas instituições onde nos inserimos, enfim, em todos os âmbitos que se relacionam com o desempenho da profissão docente, em que nível for. Os filtros que usamos são produto de nossos próprios conhecimentos, podendo atuar de forma a retirar das narrativas aspectos mais pregnantes, já que somos ao mesmo tempo atores e autores de nossos relatos, assim como quem nos lê pode se identificar e protagonizar episódios semelhantes.

As autoras deste trabalho desenvolvem pesquisas em que os sujeitos são professores em formação ou estão atuando em escolas. Esses sujeitos se dispõem a pensar suas práticas e a exercitar aspectos delas que sempre podem ser aprimorados, trazem recortes destas pesquisas para que pensemos juntos os aspectos relacionados à leitura como formação e aos processos narrativos vividos pelos que se aventuram no fazer docente de forma consciente, buscando emancipação para si e para os que com eles convivem.

\section{Narrativas de professores sobre experiências de leitura e implicações na prática docente}

O primeiro conjunto de trabalhos aqui apresentado traz trechos de uma pesquisa realizada com um grupo de nove professoras de uma escola da rede pública de ensino do Distrito Federal (DF) que atende ao segmento do ensino fundamental de primeiro ao quinto ano. Desta forma, o que se buscou junto a essas professoras foi identificar e analisar suas concepções sobre suas experiências de leitura ao longo de sua trajetória escolar, bem como compreender a existência ou não de um diálogo dessas leituras com suas práticas pedagógicas atuais. Para análise dos dados obtidos, fez-se o levantamento, a partir das narrativas das professoras, das seguintes categorias de análise: contexto das primeiras leituras, referência de leituras na escola, sentimentos em relação à leitura, concepções das relações entre memórias de leitura e a prática pedagógica.

Dentre um total de nove, seis participantes tiveram o contexto das primeiras leituras na escola. Os professores que tiveram suas primeiras experiências de 
leitura em casa (três) as relembram como boas experiências, compartilhadas por pessoas próximas, envolvendo livros e histórias. Já sobre a experiência na escola, metade relatou experiências desagradáveis, leituras mecânicas com cartilhas, e a outra metade se referiu a experiências agradáveis em que eram oferecidos livros de história e opções de escolha de leitura. A seguir, alguns trechos de narrativas relativas às categorias mencionadas acima e algumas reflexões sobre elas.

P1 - "Nas minhas primeiras séries, não tive contato com autores, tampouco com os livros. Só lia a cartilha (Ataliba) e os textos dos livros de "Comunicação e Expressão". Nada que me evocasse prazer ou fosse significativo".

P2 - "Me recordo da professora da $1^{\circ}$ série pedindo para que a turma lesse as letras do alfabeto fixados acima do quadro de giz. Isso era repetido diariamente no início da aula. Minha alfabetização, pelo que me recordo, foi constituída pela cartilha "Caminhos do Saber' que a cada dia era realizada uma parte e não poderíamos fazer adiante".

P3 - "Lembro-me de não gostar de ler por não sentir ou fazer sentido e no fundo me achar perdida nas repetidas vezes que tinha que ler o mesmo texto".

P4 - "Professor Jorge, que também era o diretor da escola, entrava em uma sala sempre com um sorriso único e uma alegria contagiante para conversar com a turma sobre o livro que iríamos ler naquele mês. Isso era o bastante para nos motivar e querer devorar o livro. E assim foram muitos durante o ano letivo: A ilha perdida, Éramos seis, A borboleta atíria, 0 escaravelho do diabo, entre outros. $E$ foram muitas viagens vividas através dos livros. Depois dessa experiência descobri o gosto pela leitura".

P5 - "A professora Elisa fez brilhantemente seu papel de mediadora, alunos e leituras diversas. Até musica do Chico Buarque ela cantava".

É importante ressaltar que a maioria das experiências formativas prazerosas em relação à leitura, seja em casa, seja na escola, foram relacionadas ao contexto favorável, não só pela qualidade afetiva, mas também pelas atividades propostas e formas em que a leitura foi apresentada, em que o estimulo, a criatividade e a imaginação eram mais valorizados que as atividades de decifração. Isso pode indicar o quanto a leitura é uma atividade transdisciplinar, transcendendo o ato da leitura, ou o conteúdo propriamente dito, e remetendo à qualidade das interações que ela propicia, às relações afetivas, às memórias, aos contextos.

Sete, dos nove professores, relatam que gostam de ler atualmente. Entretanto, metade dos entrevistados dizem que não foram estimulados pela escola, e sim por iniciativa própria. A seguir alguns depoimentos a esse respeito: 
P1 - “Em 1989 passei a frequentar a biblioteca do Santa Dorotéia, por iniciativa própria. Naquele ano, li todos os exemplares disponíveis das "Edições de Ouro". Assim, aos 12 anos, mudei de mala e cuia para dentro dos livros e não saí mais. Vale ressaltar que esse prazer lo prazer da leitural nunca foi aproveitado pelos meus professores. Tornou-se uma atividade essencial e central, porém solitária".

P5 - "Passei a sentir prazer com a leitura aos 10 anos de idade quando encontrei em cima da cama de meu irmão um livro da série vaga-lume 'ilha perdida'. A partir desse evento passei a ler todos os livros da estante".

Esses exemplos podem mostrar que a possibilidade de escolha na leitura é um fator importante para o surgimento do interesse na infância, adolescência, ou até mesmo na fase adulta, já que a (P3) relata:

“Acabei levando a leitura 'nas costas' até a faculdade, quando por acaso me emprestaram um livro '0 físico', de Noah Gordon, e descobri o prazer da leitura. Hoje adoro ler. Leio bastante".

Nessa pesquisa, destaca-se também a preferência por livros relacionados à profissão.

P6 - "Gosto de revistas voltadas à educação, projetos, e curto a revista Recreio por trazer curiosidades e atualidades para usá-las em sala de aula com meus alunos".

Das que não gostam de ler atualmente, uma relaciona ao fato de, em certo momento do ensino da leitura, esta ter se transformado em preenchimentos de fichas literárias para a escola.

P4 - "Já nas séries finais a leitura passou a ser uma cobrança e deixou um pouco de ser prazerosa. Ler para responder fichas literárias não era muito motivador".

Outro professor relaciona o não gostar de ler com a experiência de leitura ter sido desagradável em algum momento da vida escolar. Independentemente de gostar ou não de ler, três professores dizem que a leitura não foi motivada pelos professores.

As relações entre as memórias de leitura e a prática pedagógica foram estabelecidas nas narrativas das professoras tanto no sentido das experiências positivas, quanto das negativas, que elas não gostariam de repetir com seus alunos. 
P7 - "Hoje este amor pelos livros me inspira a realizar atividades de literatura com meus alunos que os estimulam e incentivam a ler".

P4 - "Os textos lidos e discutidos em sala de aula, individualmente ou em grupo, também eram momentos muito prazerosos e de profundos conhecimentos".

P4 - “A formação acadêmica não nos traz fórmulas prontas para atuar e desenvolver um trabalho pedagógico. São nossas experiências que nos norteiam".

P1 - "Durante o debate com a professora E., identifiquei muita da minha história que estavam adormecidas na minha memória. Em 22 anos de profissão sempre me reporto às lembranças dos meus professores para balizar algumas opções com meus alunos".

P6 - "Procuro não cometer os 'erros' que me entristeceram na infância com falta de atenção, de carinho, muita repressão".

Algumas professoras destacaram que foram percebendo essas relações entre suas memórias e práticas pedagógicas na medida em que construíam seus relatos. Disseram também que essas relações existiam anteriormente, mas que não eram objeto de uma análise consciente, pois este geralmente não é um objeto de reflexão dos professores. De acordo com Vygotsky (2005), a consciência dos processos reflexivos é um importante passo na direção do seu desenvolvimento e do estabelecimento de novas relações e novas possibilidades de compreensão. Nesta perspectiva, este projeto de pesquisa, além de identificar e analisar concepções de professores de ensino básico sobre suas experiências de leitura, pôde criar um espaço de autorreflexão nos sujeitos, para que pudessem vivenciar o que Vygotsky (2005) considera um importante fator de desenvolvimento, que é tomar consciência de seus próprios processos de conhecimento e formação, e nesse sentido viabilizar novas leituras sobre eles.

0 segundo conjunto de trabalhos aqui analisados faz um relato de experiência desenvolvida com um grupo de egressos de curso de licenciatura em pedagogia, que se reúne mensalmente para discutir aspectos de sua prática, rever atitudes, repensar posturas, crenças e valores e trocar recursos pedagógicos no lidar com o dia a dia das escolas públicas em que trabalham. 0 recorte é de um relato feito no diário de bordo de participantes sobre experiências pessoais de aquisição de leitura e implicações desses processos e situações vividas na prática docente atual.

Sempre a partir das memórias de formação, buscamos no grupo registrar depoimentos e trocar experiências que possam vir a fortalecer as práticas docentes 
de quem está na escola básica e precisa de apoio para validar ou reformular crenças e fazeres.

Nesses primeiros depoimentos, há alusão à magia trazida pela leitura, um aspecto com o qual concordamos sobremaneira, e ainda às práticas avaliativas vividas durante os diversos períodos escolares, o que pode ser um ponto interessante de debate, na medida em que podemos perguntar quais são as práticas avaliativas desenvolvidas por estes professores na atualidade, em sua sala de aula. Ainda temos também a questão das escolhas de leituras, que, em não sendo voluntárias, podem trazer algumas implicações para o processo de tornarse leitor, ou até mesmo tornar-se leitor de si.

"As questões às vezes me deixavam aflito, pois focavam momentos mais específicos da história lida. 0 período do Normal foi o espaço-tempo formativo em que as leituras foram mais significativas. Líamos em sala de aula coletivamente e individualmente, o acesso à biblioteca era livre, havia muito incentivo da escola para lermos. Nos tempos vagos, eu corria para a biblioteca, lia revistas variadas, jornal do dia, fazia empréstimos de obras. Eu tinha uma curiosidade por aprender coisas novas, andar por territórios desconhecidos e isso os livros me permitiam". (Prof. S)

“Revisitar a minha memória buscando os fios experienciais de leitura em minha trajetória escolar traz à tona a questão da avaliação quando relacionada ao antigo ensino primário. No ginásio não tínhamos contatos com livros, pois nem a escola possuía uma biblioteca ou sala de leitura. Já no Normal, hoje formação de professores no ensino médio, líamos bastante, desde assuntos pedagógicos, literatura e outros. Lembro, do primário, que os livros que nos debruçávamos tinham como objetivo a realização de uma prova na qual precisávamos "provar" o domínio do assunto abordado no livro, que, por sinal, não era por nós escolhido". (Prof. T)

Os depoimentos selecionados a seguir exemplificam como uma história de ser leitor pode trazer implicações na prática de professoras, assim como na consciência da importância de se terem práticas construtivas e compartilhadas. Tanto podem ser vivências anteriores à prática docente quanto experiências durante o exercício da docência, o que nos faz apostar, como Bragança (2009), nos espaços formativos narrados e refletidos como possíveis de serem vividos em diversos espaços/tempos.

“Na escola em que atuo, apresento diversos livros aos meus alunos e leio algumas páginas para inseri-los nessa dinâmica de curiosidade. Levo-os à sala de leitura, incentivo todos a folhearem as obras, converso sobre os autores. Percebo que a minha 
vivência de leitor na formação de professores dialoga com a prática pedagógica que exerço, pois quero tornar meus alunos curiosos, que encontrem também na leitura respostas às suas indagações, que possam caminhar em outros espaços, conhecer lugares novos e criar um outro contexto para suas aprendizagens". (Prof. S)

“Sobre minhas experiências de leitura, sempre gostei muito de ler e acho que passo isso para meus alunos. Não por acaso, concomitantemente com o período em que concluí a graduação, comecei a participar do Projeto Mais Educação, ministrando Oficina de Letramento. Este projeto tem a finalidade de atender aos alunos com dificuldades de aprendizagem, assim como de retirar das ruas as crianças, já que o projeto é realizado no contraturno no qual o aluno estuda. Utilizo muito minha experiência de leitora para desenvolver as atividades e vejo bons resultados. Enfim, tenho muitas expectativas em relação ao meu futuro profissional e, mais que tudo, vou tentar colocar em prática da melhor maneira possível o que aprendi na graduação, fazendo com que os textos que lemos sobre os teóricos não seja apenas uma utopia e sim uma realidade que buscamos a cada dia em busca de uma educação mais justa e igualitária". (Profa M.)

0 último depoimento selecionado reforça a cotidianidade do fazer docente, coloca em discussão a ideia da quase determinação de um passado com pouco ou nenhum acesso a materiais escritos como derivando em um não leitor. 0 fato de ter um familiar que estimule o ato de ler, no caso aqui trazido, equilibrou as influências. Outro depoimento do grupo envolvido no trabalho falava de uma figura parental semianalfabeta, mas que gostava de óperas e contava aos filhos as histórias dessas obras musicais, tradição oral que chamava para uma futura leitura, pelo deslumbramento com as histórias contadas e vividas.

"No cotidiano da escola percebo que aplico muitas coisas que aprendi, mas vou muito também na intuição, que foi sendo construída ao longo de minha experiência de 20 anos de magistério. Na minha casa não tinha acesso a livros, éramos pobres, mas meus pais sempre incentivaram que eu crescesse profissionalmente e eu fui em frente. Faço muitas atividades de leitura diretamente e indiretamente com meus alunos e estimulo minhas colegas a trabalharmos em conjunto, embora nem sempre tenha companhia. Estou sempre repensando minha caminhada profissional, buscando novas experiências e diálogos com colegas e antigos professores também; leio Nova Escola todo mês e busco atividades interessantes para meus alunos". (Profa ${ }^{\mathrm{Y}}$.) 


\section{Considerações e algumas leituras possíveis}

No conjunto, os trabalhos aqui apresentados com suas respectivas narrativas de professores trazem alguns pontos em comum que contribuem para a reflexão de que ler transcende o ato de leitura, em que a atribuição de sentidos é composta pelos mais variados aspectos que podem remeter desde a questões mais amplas, como a variação de contextos em que ela acontece, a qualidade das interações e dimensões afetivas envolvidas, até a questões mais pontuais como a possibilidade de escolha da leitura. Um outro aspecto importante se refere ao fato de que, nas duas experiências, a narrativa se revela como um importante espaço para o estabelecimento de novas relações entre memórias escolares e questões do cotidiano da prática profissional, promovendo novas possibilidades de análise e compreensão entre elas.

$\mathrm{Na}$ atualidade, muito na literatura fala da concepção de professor como profissional reflexivo. Encontramos essa formulação em Donald Schön (1992), que, tendo como fundamentação a epistemologia da prática, afirma os movimentos de produção do conhecimento na ação, reflexão na ação e reflexão sobre a reflexão na ação como constituintes da prática docente. Essa formulação tem causado grande impacto sobre as pesquisas e práticas de formação docente, pois situa o professor como sujeito e autor do processo pedagógico e da construção de saberes. O conhecimento na ação é o conhecimento demonstrado na execução da atividade; ele é tácito e coloca-se de forma espontânea no desenvolvimento das ações. Para Alarcão (1996), a reflexão sobre a ação é o processo que leva professores a se desenvolverem profissionalmente e a progredirem na forma de autoconstrução de seu conhecimento. Quando narramos, estamos refletindo sobre o que vivemos e como vivemos, em busca de entendimento e construção de conhecimento.

As narrativas são, assim, fontes de conhecimento, estimulando quem relata e quem ouve ou lê a uma reflexão sobre as vidas de outros e sua própria vida; experiências pessoais e profissionais de sucesso passam necessariamente pela capacidade de interagir, de ouvir e compreender as histórias dos que nos rodeiam e nossas próprias como constitutivas de nosso tempo e de nosso espaço de atuação.

Ao narrar experiências de vida, damos testemunhos e depoimentos de como achamos que nossa vida se desenrolou, imaginariamente, mas vivificada pela força do que deixamos entrever em recordações, reconfigurações temporais e espaciais. Combinamos esquecido e recordado, passado e presente, individual e social, fala e silêncio, opostos combinados dando um sentido ao que narramos. Produzimos significado, em qualquer forma de linguagem, lidando como nossas lembranças e histórias, nossa realidade e nossa ficção. Esse movimento libera espaços de pensar e realizar leituras do nosso fazer profissional lassim como 
outras situações que não são o foco deste trabalho, mas que acontecem também), ressignificar crenças e práticas, espaço de infinitas possibilidades de construção dos nossos diversos 'eus' que nos compõem.

De acordo com Bragança (2009), ser um profissional professor não é um pacote recebido de alguém e nem mesmo um receituário de habilidades e competências a serem perseguidas, mas envolve um intenso movimento individual e coletivo de viver e dizer o trabalho docente cotidiano, de narrá-lo na densidade de suas contradições. Complementa a autora, dizendo que não vem de forma individualizada, como autonomia no sentido de tomada de decisões isoladas pelo/a professor/a, "mas a vivência coletiva da educação vai dando o tom dos caminhos que serão trilhados por uma determinada comunidade educativa." (Bragança, 2009, p. 100). Ou seja, as respostas às diversas situações não são dadas mediante a aplicação de uma teoria e técnica preestabelecida, mas pelo saber que emana das reflexões desenvolvidas em grupos e individualmente sobre o que é ser professor e como desenvolvemos nossa atividade docente.

Ao apostarmos nas narrativas como instrumentos e meios na formação e nas práticas de professores, afirmamos que elas promovem processos individuais e coletivos de crescimento e potencialização e se constituem em mecanismos de interação que recolhem e interpretam diferentes vozes, compreendendo causas, intenções e objetivos nas ações que empreendemos em nossos fazeres cotidianos, ampliando espaços e tempos e proporcionando novas leituras da formação docente.

\section{Referências}

ALARCÃO, Isabel (Org.). Formação reflexiva de professores: estratégias de supervisão. Porto: Porto Editora, 1996.

BENJAMIN, Walter. Obras escolhidas I: Magia e Técnica, Arte e Política. São Paulo, Brasiliense, 1985.

BRAGANÇA, Inês Ferreira Souza. O/a professor/a e os espelhos da pesquisa educacional. Revista Brasileira Estudos Pedagógicos, Brasília, v. 90, n. 224, p. 87101, jan./abr. 2009.

CLANDININ, Jean.; CONNELLY, Michael. Narrative and story in practice and research. In: SCHÖN, Donald. (Ed) The reflective turn: Case studies in and on educational practice. New York: Teachers College Press, 1991, p. 258-281.

CONNELLY, Michael; CLANDININ, Jean. On narrative method, personal philosophy, and narrative unities in the story of teaching. Journal of Research in Science Teaching, New York, v. 23, n. 4, p. 293-310, 1986. 
GALVÃO, Cecília. Narrativas em Educação. Ciênc. educ. (Bauru), Bauru, v. 11, n. 2, ago. 2005. Disponível em http://www.scielo.br/scielo.php?script=sci_ arttext\&pid=S1516-73132005000200013\&lng=pt\&nrm=iso Acesso em: mar. de 2012.

LARROSA, Jorge. Notas sobre a experiência e o saber de experiência. Revista Brasileira de Educação, Rio de Janeiro, n.19, abr. 2002. Disponível em http://www. anped.org.br/rbe/rbedigital/RBDE19/RBDE19_04_JORGE_LARROSA_BONDIA.pdf Acesso em março de 2011.

LARROSA, Jorge. Literatura, experiência e formação: uma entrevista com Jorge Larrosa. In: Costa, M. V. (Org.). Caminhos investigativos: novos olhares na pesquisa em educação. Porto Alegre: Mediação, 1996, p.133-161.

SCHÖN, Donald. Formar professores como profissionais reflexivos. In: NÓvOA Antonio (Org.). Os professores e sua formação. Lisboa: Dom Quixote, 1992.

VYGOTSKY, Lev Seminovich. Pensamento e linguagem. São Paulo: Martins Fontes, 2005.

. Psicologia pedagógica. São Paulo: Martins Fontes, 2001.

A tragédia de Hamlet, príncipe da Dinamarca. São Paulo: Martins Fontes,

1999.

YUNES, Eliana. Introdução: Leitura, a complexidade do simples: do mundo à letra e de volta ao mundo. In.: Pensar a leitura: complexidade. YUNES, Eliana. (Org.). Rio de Janeiro: Ed. PUC-Rio. São Paulo: Loyola, 2005, p.13-51.

Elementos para uma história de interpretação. In.: Pensar a leitura: complexidade. YUNES, Eliana. (Org.). Rio de Janeiro: Ed. PUC-Rio. São Paulo: Loyola, 2005 p.97-103.

Recebido em julho de 2013

Aprovado em setembro de 2013

Eda Maria de Oliveira Henriques é doutora em Educação pela Universidade Federal Fluminense, Professora Associada I da Universidade Federal Fluminense e professora do Programa de Pós-graduação em Educação da UFF e da UnB. E-mail: edahenriquesdagmail.com

Helena Amaral da Fontoura é doutora em Ciências pela Escola Nacional de Saúde Pública/Fundação Oswaldo Cruz, pós-doutora em educação na Universidade de Barcelona e Professora Associada da Faculdade de Formação de Professores da Universidade do Estado do Rio de Janeiro. E-mail: helenafontourađgmail.com 